\title{
Split feasibility problems for total quasi-asymptotically nonexpansive mappings
}

\author{
Xiong Rui Wang ${ }^{1}$, Shih-sen Chang ${ }^{2 *}$, Lin Wang ${ }^{2}$ and Yun-he Zhao ${ }^{2}$
}

\section{"Correspondence:}

changss@yahoo.cn

${ }^{2}$ College of Statistics and

Mathematics, Yunnan University of

Finance and Economics, Kunming,

Yunnan 650221, China

Full list of author information is

available at the end of the article

\begin{abstract}
The purpose of this paper is to propose an algorithm for solving the split feasibility problems for total quasi-asymptotically nonexpansive mappings in infinite-dimensional Hilbert spaces. The results presented in the paper not only improve and extend some recent results of Moudafi [Nonlinear Anal. 74:4083-4087, 2011; Inverse Problem 26:055007, 2010], but also improve and extend some recent results of Xu [Inverse Problems 26:105018, 2010; 22:2021-2034, 2006], Censor and Segal [J. Convex Anal. 16:587-600, 2009], Censor et al. [Inverse Problems 21:2071-2084, 2005], Masad and Reich [J. Nonlinear Convex Anal. 8:367-371, 2007], Censor et al. [J. Math. Anal. Appl. 327:1244-1256, 2007], Yang [Inverse Problem 20:1261-1266, 2004] and others.

MSC: 47J05; 47H09; 49J25
\end{abstract}

Keywords: split feasibility problem; convex feasibility problem; total quasi-asymptotically nonexpansive mappings; demi-closeness; Opial condition

\section{Introduction}

Throughout this paper, we always assume that $H_{1}, H_{2}$ are real Hilbert spaces, ' $\rightarrow$ ', ' $\rightarrow$ ' denote strong and weak convergence, respectively, and $F(T)$ is a fixed point set of a mapping $T$.

The split feasibility problem (SFP) in finite-dimensional spaces was first introduced by Censor and Elfving [1] for modeling inverse problems which arise from phase retrievals and in medical image reconstruction [2]. Recently, it has been found that the SFP can also be used in various disciplines such as image restoration, computer tomograph and radiation therapy treatment planning [3-5]. The split feasibility problem in an infinitedimensional real Hilbert space can be found in $[2,4,6-10]$.

The purpose of this paper is to introduce and study the following split feasibility problem for total quasi-asymptotically nonexpansive mappings in the framework of infinitedimensional real Hilbert spaces:

$$
\text { find } x^{*} \in C \text { such that } A x^{*} \in Q \text {, }
$$

where $A: H_{1} \rightarrow H_{2}$ is a bounded linear operator, $S: H_{1} \rightarrow H_{1}$ and $T: H_{2} \rightarrow H_{2}$ are mappings; $C:=F(S)$ and $Q:=F(T)$. In the sequel, we use $\Gamma$ to denote the set of solutions of

\section{Springer}

(c) 2012 Wang et al.; licensee Springer. This is an Open Access article distributed under the terms of the Creative Commons Attribution License (http://creativecommons.org/licenses/by/2.0), which permits unrestricted use, distribution, and reproduction in any medium, provided the original work is properly cited. 
(SFP)-(1.1), i.e.,

$$
\Gamma=\{x \in C, A x \in Q\} .
$$

\section{Preliminaries}

We first recall some definitions, notations and conclusions which will be needed in proving our main results.

Let $E$ be a Banach space. A mapping $T: E \rightarrow E$ is said to be demi-closed at origin if for any sequence $\left\{x_{n}\right\} \subset E$ with $x_{n} \rightarrow x^{*}$ and $\left\|(I-T) x_{n}\right\| \rightarrow 0, x^{*}=T x^{*}$.

A Banach space $E$ is said to have the Opial property, if for any sequence $\left\{x_{n}\right\}$ with $x_{n} \rightarrow x^{*}$,

$$
\liminf _{n \rightarrow \infty}\left\|x_{n}-x^{*}\right\|<\liminf _{n \rightarrow \infty}\left\|x_{n}-y\right\|, \quad \forall y \in E \text { with } y \neq x^{*}
$$

Remark 2.1 It is well known that each Hilbert space possesses the Opial property.

Definition 2.2 Let $H$ be a real Hilbert space.

(1) A mapping $G: H \rightarrow H$ is said to be a $\left(\left\{v_{n}\right\},\left\{\mu_{n}\right\}, \zeta\right)$-total quasi-asymptotically nonexpansive mapping if $F(G) \neq \emptyset$; and there exist nonnegative real sequences $\left\{v_{n}\right\},\left\{\mu_{n}\right\}$ with $v_{n} \rightarrow 0$ and $\mu_{n} \rightarrow 0$ and a strictly increasing continuous function $\zeta: \mathcal{R}^{+} \rightarrow \mathcal{R}^{+}$with $\zeta(0)=0$ such that for each $n \geq 1$,

$$
\left\|p-G^{n} x\right\|^{2} \leq\|p-x\|^{2}+v_{n} \zeta(\|p-x\|)+\mu_{n}, \quad \forall p \in F(G), x \in H .
$$

Now, we give an example of total quasi-asymptotically nonexpansive mapping.

Let $C$ be a unit ball in a real Hilbert space $l^{2}$, and let $T: C \rightarrow C$ be a mapping defined by

$$
T:\left(x_{1}, x_{2}, \ldots,\right) \rightarrow\left(0, x_{1}^{2}, a_{2} x_{2}, a_{3} x_{3}, \ldots\right),\left(x_{1}, x_{2}, \ldots,\right) \in l^{2}
$$

where $\left\{a_{i}\right\}$ is a sequence in $(0,1)$ such that $\prod_{i=2}^{\infty} a_{i}=\frac{1}{2}$.

It is proved in Goebal and Kirk [17] that

(i) $\|T x-T y\| \leq 2\|x-y\|, \forall x, y \in C$;

(ii) $\left\|T^{n} x-T^{n} y\right\| \leq 2 \prod_{j=2}^{n} a_{j}\|x-y\|, \forall x, y \in C, \forall n \geq 2$.

Denote by $k_{1}^{\frac{1}{2}}=2, k_{n}^{\frac{1}{2}}=2 \prod_{j=2}^{n} a_{j}, n \geq 2$, then

$$
\lim _{n \rightarrow \infty} k_{n}=\lim _{n \rightarrow \infty}\left(2 \prod_{j=2}^{n} a_{j}\right)^{2}=1 .
$$

Letting $v_{n}=\left(k_{n}-1\right), \forall n \geq 1, \zeta(t)=t, \forall t \geq 0$ and $\left\{\mu_{n}\right\}$ be a nonnegative real sequence with $\mu_{n} \rightarrow 0$, from (i) and (ii), $\forall x, y \in C, n \geq 1$, we have

$$
\left\|T^{n} x-T^{n} y\right\|^{2} \leq\|x-y\|^{2}+v_{n} \zeta\left(\|x-y\|^{2}\right)+\mu_{n}
$$

Again, since $0 \in C$ and $0 \in F(T)$, this implies that $F(T) \neq \emptyset$. From (2.2), we have

$$
\left\|p-T^{n} y\right\|^{2} \leq\|p-y\|^{2}+v_{n} \zeta\left(\|p-y\|^{2}\right)+\mu_{n} \quad \forall p \in F(T), y \in C .
$$


This shows that the mapping $T$ defined as above is a total quasi-asymptotically nonexpansive mapping.

(2) A mapping $G: H \rightarrow H$ is said to be $\left(\left\{k_{n}\right\}\right)$-quasi-asymptotically nonexpansive if $F(G) \neq \emptyset$; and there exists a sequence $\left\{k_{n}\right\} \subset[1, \infty)$ with $k_{n} \rightarrow 1$ such that for all $n \geq 1$,

$$
\left\|p-G^{n} x\right\|^{2} \leq k_{n}\|p-x\|^{2}, \quad \forall p \in F(G), x \in H .
$$

(3) A mapping $G: H \rightarrow H$ is said to be quasi-nonexpansive if $F(G) \neq \emptyset$ such that

$$
\|p-G x\| \leq\|p-x\|, \quad \forall p \in F(G), x \in H .
$$

Remark 2.3 It is easy to see that every quasi-nonexpansive mapping is a (\{1\})-quasiasymptotically nonexpansive mapping and every $\left\{k_{n}\right\}$-quasi-asymptotically nonexpansive mapping is a $\left(\left\{v_{n}\right\},\left\{\mu_{n}\right\}, \zeta\right)$-total quasi-asymptotically nonexpansive mapping with $\left\{v_{n}=k_{n}-1\right\},\left\{\mu_{n}=0\right\}$ and $\zeta(t)=t^{2}, t \geq 0$.

\section{Definition 2.4}

(1) A mapping $G: H \rightarrow H$ is said to be uniformly $L$-Lipschitzian if there exists a constant $L>0$ such that

$$
\left\|T^{n} x-T^{n} y\right\| \leq L\|x-y\|, \quad \forall x, y \in H \text { and } n \geq 1 .
$$

(2) A mapping $G: H \rightarrow H$ is said to be semi-compact if for any bounded sequence $\left\{x_{n}\right\} \subset H$ with $\lim _{n \rightarrow \infty}\left\|x_{n}-G x_{n}\right\|=0$, there exists a subsequence $\left\{x_{n_{i}}\right\} \subset\left\{x_{n}\right\}$ such that $x_{n_{i}}$ converges strongly to some point $x^{*} \in H$.

Proposition 2.5 Let $G: H \rightarrow H$ be a $\left(\left\{v_{n}\right\},\left\{\mu_{n}\right\}, \zeta\right)$-total quasi-asymptotically nonexpansive mapping. Then for each $q \in F(G)$ and for each $x \in H$, the following inequalities are equivalent: for each $n \geq 1$

$$
\begin{aligned}
& \left\|q-G^{n} x\right\|^{2} \leq\|q-x\|^{2}+v_{n} \zeta(\|q-x\|)+\mu_{n}, \quad \forall q \in F(G), x \in H ; \\
& 2\left\langle x-G^{n} x, x-q\right\rangle \geq\left\|x-G^{n} x\right\|^{2}-v_{n} \zeta(\|q-x\|)-\mu_{n} ; \\
& 2\left\langle x-G^{n} x, q-G^{n} x\right\rangle \leq\left\|x-G^{n} x\right\|^{2}+v_{n} \zeta(\|q-x\|)+\mu_{n} .
\end{aligned}
$$

Proof

(I) $(2.1) \Leftrightarrow(2.6)$ In fact, since

$$
\begin{aligned}
\left\|G^{n} x-q\right\|^{2} & =\left\|G^{n} x-x+x-q\right\|^{2} \\
& =\left\|G^{n} x-x\right\|^{2}+\|x-q\|^{2}+2\left\langle G^{n} x-x, x-q\right\rangle, \quad \forall x \in H, q \in F(G),
\end{aligned}
$$

from (2.1) we have that

$$
\begin{aligned}
& \left\|G^{n} x-x\right\|^{2}+\|x-q\|^{2}+2\left\langle G^{n} x-x, x-q\right\rangle \\
& \leq\|x-q\|^{2}+v_{n} \zeta(\|q-x\|)+\mu_{n} .
\end{aligned}
$$


Simplifying it, inequality (2.6) is obtained.

Conversely, from (2.6) the inequality (2.1) can be obtained immediately.

(II) $(2.6) \Leftrightarrow(2.7)$ In fact, since

$$
\begin{aligned}
\left\langle x-G^{n} x, x-q\right\rangle & =\left\langle x-G^{n} x, x-G^{n} x+G^{n} x-q\right\rangle \\
& =\left\|x-G^{n} x\right\|^{2}+\left\langle x-G^{n} x, G^{n} x-q\right\rangle
\end{aligned}
$$

it follows from (2.6) that

$$
2\left(\left\|x-G^{n} x\right\|^{2}+\left\langle x-G^{n} x, G^{n} x-q\right\rangle\right) \geq\left\|x-G^{n} x\right\|^{2}-v_{n} \zeta(\|q-x\|)-\mu_{n} .
$$

Simplifying it, the inequality (2.7) is obtained.

Conversely, from (2.7) the inequality (2.6) can be obtained immediately.

This completes the proof of Proposition 2.5.

Lemma 2.6 [11] Let $\left\{a_{n}\right\},\left\{b_{n}\right\}$ and $\left\{\delta_{n}\right\}$ be sequences of nonnegative real numbers satisfying

$$
a_{n+1} \leq\left(1+\delta_{n}\right) a_{n}+b_{n}, \quad \forall n \geq 1
$$

If $\sum_{i=1}^{\infty} \delta_{n}<\infty$ and $\sum_{i=1}^{\infty} b_{n}<\infty$, then the limit $\lim _{n \rightarrow \infty} a_{n}$ exists.

\section{Split feasibility problem}

For solving the split feasibility problem (1.1), let us assume that the following conditions are satisfied:

1. $H_{1}$ and $H_{2}$ are two real Hilbert spaces, $A: H_{1} \rightarrow H_{2}$ is a bounded linear operator;

2. $S: H_{1} \rightarrow H_{1}$ and $T: H_{2} \rightarrow H_{2}$ are two uniformly $L$-Lipschitzian and

$\left(\left\{v_{n}\right\},\left\{\mu_{n}\right\}, \zeta\right)$-total quasi-asymptotically nonexpansive mappings satisfying the following conditions:

(i) $T$ and $S$ both are demi-closed at origin;

(ii) $\sum_{n=1}^{\infty}\left(\mu_{n}+v_{n}\right)<\infty$;

(iii) there exist positive constants $M$ and $M^{*}$ such that $\zeta(t) \leq \zeta(M)+M^{*} t^{2}, \forall t \geq 0$.

We are now in a position to give the following result.

Theorem 3.1 Let $H_{1}, H_{2}, A, S, T, L,\left\{\mu_{n}\right\},\left\{v_{n}\right\}, \zeta$ be the same as above. Let $\left\{x_{n}\right\}$ be the sequence generated by:

$$
\left\{\begin{array}{l}
x_{1} \in H_{1} \quad \text { chosen arbitrarily, } \\
x_{n+1}=\left(1-\alpha_{n}\right) u_{n}+\alpha_{n} S^{n}\left(u_{n}\right), \\
u_{n}=x_{n}+\gamma A^{*}\left(T^{n}-I\right) A x_{n}, \quad \forall n \geq 1,
\end{array}\right.
$$

where $\left\{\alpha_{n}\right\}$ is a sequence in $[0,1]$, and $\gamma>0$ is a constant satisfying the following conditions:

(iv) $0<\liminf _{n \rightarrow \infty} \alpha_{n} \leq \lim \sup _{n \rightarrow \infty} \alpha_{n}<1$; and $\gamma \in\left(0, \frac{1}{\|A\|^{2}}\right)$,

(I) If $\Gamma \neq \emptyset$ (where $\Gamma$ is the set of solutions to ((SFP)-(1.1)), then $\left\{x_{n}\right\}$ converges weakly to a point $x^{\prime \prime} \in \Gamma$.

(II) In addition, if $S$ is also semi-compact, then $\left\{x_{n}\right\}$ and $\left\{u_{n}\right\}$ both converge strongly to $x^{*} \in \Gamma$. 
The proof of conclusion (I)

(1) First, we prove that for each $p \in \Gamma$, the following limits exist:

$$
\lim _{n \rightarrow \infty}\left\|x_{n}-p\right\|=\lim _{n \rightarrow \infty}\left\|u_{n}-p\right\|
$$

In fact, since $p \in \Gamma$, we have $p \in C:=F(S)$ and $A p \in Q:=F(T)$. It follows from (3.1) and (2.4) that

$$
\begin{aligned}
\left\|x_{n+1}-p\right\|^{2}= & \left\|u_{n}-p-\alpha_{n}\left(u_{n}-S^{n} u_{n}\right)\right\|^{2} \\
= & \left\|u_{n}-p\right\|^{2}-2 \alpha_{n}\left\langle u_{n}-p, u_{n}-S^{n} u_{n}\right\rangle+\alpha_{n}^{2}\left\|u_{n}-S^{n} u_{n}\right\|^{2} \\
\leq & \left\|u_{n}-p\right\|^{2}-\alpha_{n}\left\{\left\|u_{n}-S^{n} u_{n}\right\|^{2}-v_{n} \zeta\left(\left\|u_{n}-p\right\|\right)-\mu_{n}\right\} \\
& \quad+\alpha_{n}^{2}\left\|u_{n}-S^{n} u_{n}\right\|^{2} \quad(\text { by }(2.6)) \\
= & \left\|u_{n}-p\right\|^{2}-\alpha_{n}\left(1-\alpha_{n}\right)\left\|u_{n}-S^{n} u_{n}\right\|^{2}+\alpha_{n}\left(v_{n} \zeta\left(\left\|u_{n}-p\right\|\right)+\mu_{n}\right) .
\end{aligned}
$$

On the other hand, by condition (iii), we have

$$
\zeta\left(\left\|u_{n}-p\right\|\right) \leq \zeta(M)+M^{*}\left\|u_{n}-p\right\|^{2}
$$

Substituting (3.4) into (3.3) and simplifying, we have

$$
\begin{aligned}
\left\|x_{n+1}-p\right\|^{2} \leq & \left(1+\alpha_{n} v_{n} M^{*}\right)\left\|u_{n}-p\right\|^{2}-\alpha_{n}\left(1-\alpha_{n}\right)\left\|u_{n}-S^{n} u_{n}\right\|^{2} \\
& +\alpha_{n}\left(v_{n} \zeta(M)+\mu_{n}\right) \\
\leq & \left(1+v_{n} M^{*}\right)\left\|u_{n}-p\right\|^{2}-\alpha_{n}\left(1-\alpha_{n}\right)\left\|u_{n}-S^{n} u_{n}\right\|^{2}+v_{n} \zeta(M)+\mu_{n} .
\end{aligned}
$$

On the other hand,

$$
\begin{aligned}
\left\|u_{n}-p\right\|^{2} & =\left\|x_{n}-p+\gamma A^{*}\left(T^{n}-I\right) A x_{n}\right\|^{2} \\
& =\left\|x_{n}-p\right\|^{2}+\gamma^{2}\left\|A^{*}\left(T^{n}-I\right) A x_{n}\right\|^{2}+2 \gamma\left\langle x_{n}-p, A^{*}\left(T^{n}-I\right) A x_{n}\right\rangle,
\end{aligned}
$$

and

$$
\begin{aligned}
\gamma^{2}\left\|A^{*}\left(T^{n}-I\right) A x_{n}\right\|^{2} & =\gamma^{2}\left\langle A^{*}\left(T^{n}-I\right) A x_{n}, A^{*}\left(T^{n}-I\right) A x_{n}\right\rangle \\
& =\gamma^{2}\left\langle A A^{*}\left(T^{n}-I\right) A x_{n},\left(T^{n}-I\right) A x_{n}\right\rangle \\
& \leq \gamma^{2}\|A\|^{2}\left\|T^{n} A x_{n}-A x_{n}\right\|^{2},
\end{aligned}
$$

and

$$
\begin{aligned}
& 2 \gamma\left\langle x_{n}-p, A^{*}\left(T^{n}-I\right) A x_{n}\right\rangle \\
& \quad=2 \gamma\left\langle A x_{n}-A p,\left(T^{n}-I\right) A x_{n}\right\rangle \\
& \quad=2 \gamma\left\langle A x_{n}-A p+\left(T^{n}-I\right) A x_{n}-\left(T^{n}-I\right) A x_{n},\left(T^{n}-I\right) A x_{n}\right\rangle \\
& \quad=2 \gamma\left\{\left\langle T^{n} A x_{n}-A p, T^{n} A x_{n}-A x_{n}\right\rangle-\left\|\left(T^{n}-I\right) A x_{n}\right\|^{2}\right\} .
\end{aligned}
$$


In (2.5), taking $x=A x_{n}, G^{n}=T^{n}, q=A p$, and noting $A p \in F(T)$, from (2.7) and condition (iii), we have

$$
\begin{aligned}
& \left\langle T^{n} A x_{n}-A p, T^{n} A x_{n}-A x_{n}\right\rangle \\
& \quad \leq \frac{1}{2}\left\{\left\|\left(T^{n}-I\right) A x_{n}\right\|^{2}+v_{n} \zeta\left(\left\|A x_{n}-A p\right\|\right)+\mu_{n}\right\} \\
& \quad \leq \frac{1}{2}\left\{\left\|\left(T^{n}-I\right) A x_{n}\right\|^{2}+v_{n}\left(\zeta(M)+M^{*}\|A\|^{2}\left\|x_{n}-p\right\|^{2}\right)+\mu_{n}\right\} .
\end{aligned}
$$

Substituting (3.9) into (3.8) and simplifying it, we have

$$
\begin{aligned}
& 2 \gamma\left(x_{n}-p, A^{*}\left(T^{n}-I\right) A x_{n}\right\rangle \\
& \quad \leq \gamma\left\{v_{n}\left(\zeta(M)+M^{*}\|A\|^{2}\left\|x_{n}-p\right\|^{2}\right)+\mu_{n}-\left\|\left(T^{n}-I\right) A x_{n}\right\|^{2}\right\} .
\end{aligned}
$$

Substituting (3.7) and (3.10) into (3.6) after simplifying, we have

$$
\begin{aligned}
\left\|u_{n}-p\right\|^{2} \leq & \left(1+\gamma v_{n} M^{*}\|A\|^{2}\right)\left\|x_{n}-p\right\|^{2}+\gamma\left(v_{n} \zeta(M)+\mu_{n}\right) \\
& -\gamma\left(1-\gamma\|A\|^{2}\right)\left\|\left(T^{n}-I\right) A x_{n}\right\|^{2}
\end{aligned}
$$

Substituting (3.11) into (3.5) and simplifying it, we have

$$
\begin{aligned}
\left\|x_{n+1}-p\right\|^{2} \leq & \left(1+v_{n} M^{*}\right)\left\{\left(1+\gamma v_{n} M^{*}\|A\|^{2}\right)\left\|x_{n}-p\right\|^{2}\right. \\
& \left.+\gamma\left(v_{n} \zeta(M)+\mu_{n}\right)-\gamma\left(1-\gamma\|A\|^{2}\right)\left\|\left(T^{n}-I\right) A x_{n}\right\|^{2}\right\} \\
& -\alpha_{n}\left(1-\alpha_{n}\right)\left\|u_{n}-S^{n} u_{n}\right\|^{2}+v_{n} \zeta(M)+\mu_{n} \\
\leq & \left(1+\xi_{n}\right)\left\|x_{n}-p\right\|^{2}+\eta_{n}-\gamma\left(1-\gamma\|A\|^{2}\right)\left\|\left(T^{n}-I\right) A x_{n}\right\|^{2} \\
& -\alpha_{n}\left(1-\alpha_{n}\right)\left\|u_{n}-S^{n} u_{n}\right\|^{2}
\end{aligned}
$$

where

$$
\begin{aligned}
& \xi_{n}=v_{n}\left(M^{*}+\gamma M^{*}\|A\|^{2}+\gamma v_{n} M^{*}\|A\|^{2}\right), \\
& \eta_{n}=\left[\left(1+v_{n} M^{*}\right) \gamma+1\right]\left(v_{n} \zeta(M)+\mu_{n}\right) .
\end{aligned}
$$

By condition (iii), we have

$$
\sum_{n=1}^{\infty} \xi_{n}<\infty, \quad \text { and } \quad \sum_{n=1}^{\infty} \eta_{n}<\infty
$$

By condition (iv), $\left(1-\gamma\|A\|^{2}\right)>0$. Hence, from (3.12), we have

$$
\left\|x_{n+1}-p\right\|^{2} \leq\left(1+\xi_{n}\right)\left\|x_{n}-p\right\|^{2}+\eta_{n}, \quad \forall n \geq 1
$$

By Lemma 2.6, the following limit exists:

$$
\lim _{n \rightarrow \infty}\left\|x_{n}-p\right\|
$$


Now, we rewrite (3.12) as follows:

$$
\begin{aligned}
& \gamma\left(1-\gamma\|A\|^{2}\right)\left\|\left(T^{n}-I\right) A x_{n}\right\|^{2}+\alpha_{n}\left(1-\alpha_{n}\right)\left\|u_{n}-S^{n} u_{n}\right\|^{2} \\
& \leq\left\|x_{n}-p\right\|^{2}-\left\|x_{n+1}-p\right\|^{2} \\
& \quad+\xi_{n}\left\|x_{n}-p\right\|^{2}+\eta_{n} \rightarrow 0 \quad(\text { as } n \rightarrow \infty) .
\end{aligned}
$$

This together with the condition (iv) implies that

$$
\lim _{n \rightarrow \infty}\left\|u_{n}-S^{n} u_{n}\right\|=0
$$

and

$$
\lim _{n \rightarrow \infty}\left\|\left(T^{n}-I\right) A x_{n}\right\|=0 .
$$

It follows from (3.6), (3.14) and (3.15) that the limit $\lim _{n \rightarrow \infty}\left\|u_{n}-p\right\|$ exists and

$$
\lim _{n \rightarrow \infty}\left\|u_{n}-p\right\|=\lim _{n \rightarrow \infty}\left\|x_{n}-p\right\|
$$

The conclusion (3.2) is proved.

(2) Next, we prove that

$$
\lim _{n \rightarrow \infty}\left\|x_{n+1}-x_{n}\right\|=0 \text { and } \quad \lim _{n \rightarrow \infty}\left\|u_{n+1}-u_{n}\right\|=0
$$

In fact, it follows from (3.1) that

$$
\begin{aligned}
\left\|x_{n+1}-x_{n}\right\| & =\left\|\left(1-\alpha_{n}\right) u_{n}+\alpha_{n} S^{n}\left(u_{n}\right)-x_{n}\right\| \\
& =\left\|\left(1-\alpha_{n}\right)\left(x_{n}+\gamma A^{*}\left(T^{n}-I\right) A x_{n}\right)+\alpha_{n} S^{n}\left(u_{n}\right)-x_{n}\right\| \\
& =\left\|\left(1-\alpha_{n}\right) \gamma A^{*}\left(T^{n}-I\right) A x_{n}+\alpha_{n}\left(S^{n}\left(u_{n}\right)-x_{n}\right)\right\| \\
& =\left\|\left(1-\alpha_{n}\right) \gamma A^{*}\left(T^{n}-I\right) A x_{n}+\alpha_{n}\left(S^{n}\left(u_{n}\right)-u_{n}\right)+\alpha_{n}\left(u_{n}-x_{n}\right)\right\| \\
& =\left\|\left(1-\alpha_{n}\right) \gamma A^{*}\left(T^{n}-I\right) A x_{n}+\alpha_{n}\left(S^{n}\left(u_{n}\right)-u_{n}\right)+\alpha_{n} \gamma A^{*}\left(T^{n}-I\right) A x_{n}\right\| \\
& =\left\|\gamma A^{*}\left(T^{n}-I\right) A x_{n}+\alpha_{n}\left(S^{n}\left(u_{n}\right)-u_{n}\right)\right\| .
\end{aligned}
$$

In view of (3.14) and (3.15), we have that

$$
\lim _{n \rightarrow \infty}\left\|x_{n+1}-x_{n}\right\|=0
$$

Similarly, it follows from (3.1), (3.15) and (3.17) that

$$
\begin{aligned}
\left\|u_{n+1}-u_{n}\right\|= & \left\|x_{n+1}+\gamma A^{*}\left(T^{n+1}-I\right) A x_{n+1}-\left(x_{n}+\gamma A^{*}\left(T^{n}-I\right) A x_{n}\right)\right\| \\
\leq & \left\|x_{n+1}-x_{n}\right\|+\gamma\left\|A^{*}\left(T^{n+1}-I\right) A x_{n+1}\right\| \\
& +\gamma\left\|A^{*}\left(T^{n}-I\right) A x_{n}\right\| \rightarrow 0 \quad(\text { as } n \rightarrow \infty) .
\end{aligned}
$$

The conclusion (3.16) is proved. 
(3) Next, we prove that

$$
\left\|u_{n}-S u_{n}\right\| \rightarrow 0 \quad \text { and } \quad\left\|A x_{n}-T A x_{n}\right\| \rightarrow 0 \quad(\text { as } n \rightarrow \infty)
$$

In fact, from (3.14), we have

$$
\zeta_{n}:=\left\|u_{n}-S^{n} u_{n}\right\| \rightarrow 0 \quad(\text { as } n \rightarrow \infty)
$$

Since $S$ is uniformly $L$-Lipschitzian continuous, it follows from (3.16) and (3.20) that

$$
\begin{aligned}
\left\|u_{n}-S u_{n}\right\| \leq & \left\|u_{n}-S^{n} u_{n}\right\|+\left\|S^{n} u_{n}-S u_{n}\right\| \\
\leq & \zeta_{n}+L\left\|S^{n-1} u_{n}-u_{n}\right\| \\
\leq & \zeta_{n}+L\left\{\left\|S^{n-1} u_{n}-S^{n-1} u_{n-1}\right\|\right. \\
& \left.\quad+\left\|S^{n-1} u_{n-1}-u_{n}\right\|\right\} \\
\leq & \zeta_{n}+L^{2}\left\|u_{n}-u_{n-1}\right\| \\
& \quad+L\left\|S^{n-1} u_{n-1}-u_{n-1}+u_{n-1}-u_{n}\right\| \\
\leq & \zeta_{n}+L(1+L)\left\|u_{n}-u_{n-1}\right\|+L \zeta_{n-1} \rightarrow 0 \quad(\text { as } n \rightarrow \infty) .
\end{aligned}
$$

Similarly, from (3.15), we have

$$
\left\|A x_{n}-T^{n} A x_{n}\right\| \rightarrow 0 \quad(\text { as } n \rightarrow \infty) .
$$

Since $T$ is uniformly $L$-Lipschitzian continuous, by the same way as above, from (3.16) and (3.21), we can also prove that

$$
\left\|A x_{n}-T A x_{n}\right\| \rightarrow 0 \quad(\text { as } n \rightarrow \infty) .
$$

(4) Finally, we prove that $x_{n} \rightarrow x^{*}$ and $u_{n} \rightarrow x^{*}$, which is a solution of (SFP)-(1.1).

Since $\left\{u_{n}\right\}$ is bounded, there exists a subsequence $\left\{u_{n_{i}}\right\} \subset\left\{u_{n}\right\}$ such that $u_{n_{i}} \rightarrow x^{*}$ (some point in $H_{1}$ ). From (3.19), we have

$$
\left\|u_{n_{i}}-S u_{n_{i}}\right\| \rightarrow 0 \quad\left(\text { as } n_{i} \rightarrow \infty\right)
$$

By the assumption that $S$ is demi-closed at zero, we get that $x^{*} \in F(S)$.

Moreover, from (3.1) and (3.15), we have

$$
x_{n_{i}}=u_{n_{i}}-\gamma A^{*}\left(T^{n_{i}}-I\right) A x_{n_{i}} \rightarrow x^{*} .
$$

Since $A$ is a linear bounded operator, we get $A x_{n_{i}} \rightarrow A x^{*}$. In view of (3.19), we have

$$
\left\|A x_{n_{i}}-T A x_{n_{i}}\right\| \rightarrow 0 \quad\left(\text { as } n_{i} \rightarrow \infty\right)
$$

Since $T$ is demi-closed at zero, we have $A x^{*} \in F(T)$. Summing up the above argument, it is clear that $x^{*} \in \Gamma$, i.e., $x^{*}$ is a solution to the (SFP)-(1.1). 
Now, we prove that $x_{n} \rightarrow x^{*}$ and $u_{n} \rightarrow x^{*}$.

Suppose, to the contrary, that if there exists another subsequence $\left\{u_{n_{j}}\right\} \subset\left\{u_{n}\right\}$ such that $u_{n_{j}} \rightarrow y^{*} \in \Gamma$ with $y^{*} \neq x^{*}$, then by virtue of (3.2) and the Opial property of Hilbert space, we have

$$
\begin{aligned}
\liminf _{n_{i} \rightarrow \infty}\left\|u_{n_{i}}-x^{*}\right\| & <\liminf _{n_{i} \rightarrow \infty}\left\|u_{n_{i}}-y^{*}\right\|=\lim _{n \rightarrow \infty}\left\|u_{n}-y^{*}\right\| \\
& =\lim _{n_{j} \rightarrow \infty}\left\|u_{n_{j}}-y^{*}\right\|<\liminf _{n_{j} \rightarrow \infty}\left\|u_{n_{j}}-x^{*}\right\| \\
& =\lim _{n \rightarrow \infty}\left\|u_{n}-x^{*}\right\|=\liminf _{n_{i} \rightarrow \infty}\left\|u_{n_{i}}-x^{*}\right\| .
\end{aligned}
$$

This is a contradiction. Therefore, $u_{n} \rightarrow x^{*}$. By using (3.1) and (3.15), we have

$$
x_{n}=u_{n}-\gamma A^{\prime \prime}\left(T_{n}^{n}-I\right) A x_{n}-x^{*} .
$$

The proof of conclusion (II) By the assumption that $S$ is semi-compact, it follows from (3.23) that there exists a subsequence of $\left\{u_{n_{i}}\right\}$ (without loss of generality, we still denote it by $\left\{u_{n_{i}}\right\}$ ) such that $u_{n_{i}} \rightarrow u^{*} \in H$ (some point in $H$ ). Since $u_{n_{i}} \rightarrow x^{*}$. This implies that $x^{\prime \prime}=u^{\prime \prime}$, and so $u_{n_{i}} \rightarrow x^{*} \in \Gamma$. By virtue of (3.2), we know that $\lim _{n \rightarrow \infty}\left\|u_{n}-x^{*}\right\|=0$ and $\lim _{n \rightarrow \infty}\left\|x_{n}-x^{*}\right\|=0$, i.e., $\left\{u_{n}\right\}$ and $\left\{x_{n}\right\}$ both converge strongly to $x^{*} \in \Gamma$.

This completes the proof of Theorem 3.1.

Theorem 3.2 Let $H_{1}, H_{2}$ and $A$ be the same as in Theorem 3.1. Let $S: H_{1} \rightarrow H_{1}$ and $T:$ $\mathrm{H}_{2} \rightarrow \mathrm{H}_{2}$ be two $\left(\left\{k_{n}\right\}\right)$-quasi-asymptotically nonexpansive mappings with $\left\{k_{n}\right\} \subset[1, \infty)$, $k_{n} \rightarrow 1$ satisfying the following conditions:

(i) $T$ and $S$ both are demi-closed at origin;

(ii) $\sum_{n=1}^{\infty}\left(k_{n}-1\right)<\infty$

Let $\left\{x_{n}\right\}$ be the sequence generated by

$$
\left\{\begin{array}{l}
x_{1} \in H_{1} \quad \text { chosen arbitrarily, } \\
x_{n+1}=\left(1-\alpha_{n}\right) u_{n}+\alpha_{n} S^{n}\left(u_{n}\right), \\
u_{n}=x_{n}+\gamma A^{*}\left(T^{n}-I\right) A x_{n}, \quad \forall n \geq 1
\end{array}\right.
$$

where $\left\{\alpha_{n}\right\}$ is a sequence in $[0,1]$ and $\gamma>0$ is a constant satisfying the condition (iv) in Theorem 3.1. Then the conclusions in Theorem 3.1 still hold.

Proof By assumptions, $S: H_{1} \rightarrow H_{1}$ and $T: H_{2} \rightarrow H_{2}$ both are ( $\left.\left\{k_{n}\right\}\right)$-quasi-asymptotically nonexpansive mappings with $\left\{k_{n}\right\} \subset[1, \infty), k_{n} \rightarrow 1$; by Remark $2.3, S$ and $T$ both are uniformly $L$-Lipschitzian (where $L=\sup _{n \geq 1} k_{n}$ ) and $\left(\left\{v_{n}\right\},\left\{\mu_{n}\right\}, \zeta\right.$ )-total quasi-asymptotically nonexpansive mapping with $\left\{v_{n}=k_{n}-1\right\},\left\{\mu_{n}=0\right\}$ and $\zeta(t)=t^{2}, t \geq 0$. Therefore, all conditions in Theorem 3.1 are satisfied. The conclusions of Theorem 3.2 can be obtained from Theorem 3.1 immediately.

Theorem 3.3 Let $H_{1}, H_{2}$ and $A$ be the same as in Theorem 3.1. Let $S: H_{1} \rightarrow H_{1}$ and $T:$ $\mathrm{H}_{2} \rightarrow \mathrm{H}_{2}$ be two quasi-nonexpansive mappings and demi-closed at origin. Let $\left\{x_{n}\right\}$ be the 
sequence generated by

$$
\left\{\begin{array}{l}
x_{1} \in H_{1} \quad \text { chosen arbitrarily, } \\
x_{n+1}=\left(1-\alpha_{n}\right) u_{n}+\alpha_{n} S^{n}\left(u_{n}\right), \\
u_{n}=x_{n}+\gamma A^{*}\left(T^{n}-I\right) A x_{n}, \quad \forall n \geq 1,
\end{array}\right.
$$

where $\left\{\alpha_{n}\right\}$ is a sequence in $[0,1]$ and $\gamma>0$ is a constant satisfying the condition (iv) in Theorem 3.1. Then the conclusions in Theorem 3.1 still hold.

Proof By the assumptions, $S: H_{1} \rightarrow H_{1}$ and $T: H_{2} \rightarrow H_{2}$ are quasi-nonexpansive mappings. By Remark 2.3, $S$ and $T$ both are uniformly $L$-Lipschitzian (where $L=1$ ) and ( $\{1\}$ )quasi-asymptotically nonexpansive mappings. Therefore, all conditions in Theorem 3.2 are satisfied. The conclusions of Theorem 3.3 can be obtained from Theorem 3.2 immediately.

Remark 3.4 Theorems 3.1, 3.2 and 3.3 not only improve and extend the corresponding results of Moudafi [12,13], but also improve and extend the corresponding results of Censor et al. [4, 5], Yang [7], Xu [14], Censor and Segal [15], Masad and Reich [16] and others.

Competing interests

The authors declare that they have no competing interests.

Authors' contributions

All authors contributed to this work equal. All authors read and ap- proved the final manuscript.

\section{Author details}

${ }^{1}$ Department of Mathematics, Yibin University, Yibin, Sichuan 644007, China. ${ }^{2}$ College of Statistics and Mathematics, Yunnan University of Finance and Economics, Kunming, Yunnan 650221, China.

\section{Acknowledgements}

This work was supported by the Scientific Research Fund of Science Technology Department of Sichuan Province

(2011JYZ010) and the Natural Science Foundation of Yunnan Province (Grant No.2011FB074).

Received: 23 April 2012 Accepted: 30 August 2012 Published: 18 September 2012

\section{References}

1. Censor, Y, Elfving, T: A multi-projection algorithm using Bregman projections in a product space. Numer. Algorithms 8, 221-239 (1994)

2. Byrne, C: Iterative oblique projection onto convex subsets and the split feasibility problem. Inverse Probl. 18, 441-453 (2002)

3. Censor, Y, Bortfeld, T, Martin, B, Trofimov, A: A unified approach for inversion problem in intensity-modulated radiation therapy. Phys. Med. Biol. 51, 2353-2365 (2006)

4. Censor, Y, Elfving, T, Kopf, N, Bortfeld, T: The multiple-sets split feasibility problem and its applications. Inverse Probl. 21, 2071-2084 (2005)

5. Censor, Y, Motova, A, Segal, A: Perturbed projections and subgradient projections for the multiple-sets split feasibility problem. J. Math. Anal. Appl. 327, 1244-1256 (2007)

6. Xu, HK: A variable Krasnosel'skii-Mann algorithm and the multiple-sets split feasibility problem. Inverse Probl. 22, 2021-2034 (2006)

7. Yang, Q: The relaxed CQ algorithm for solving the split feasibility problem. Inverse Probl. 20, 1261-1266 (2004)

8. Zhao, J, Yang, Q: Several solution methods for the split feasibility problem. Inverse Probl. 21, 1791-1799 (2005)

9. Chang, SS, Cho, YJ, Kim, JK, Zhang, WB, Yang, L: Multiple-set split feasibility problems for asymptotically strict pseudocontractions. Abstr. Appl. Anal. 2012, Article ID 491760 (2012). doi:10:1155/2012/491760

10. Chang, SS, Wang, L, Tang, YK, Yang, L: The split common fixed point problem for total asymptotically strictly pseudocontractive mappings. J. Appl. Math. 2012, Article ID 385638 (2012). doi:10.1155/2012/385638

11. Aoyama, K, Kimura, W, Takahashi, W, Toyoda, M: Approximation of common fixed points of accountable family of nonexpansive mappings on a Banach space. Nonlinear Anal. 67(8), 2350-2360 (2007)

12. Moudafi, A: The split common fixed point problem for demi-contractive mappings. Inverse Probl. 26, 055007 (2010)

13. Moudafi, A: A note on the split common fixed point problem for quasi-nonexpansive operators. Nonlinear Anal. 74 4083-4087 (2011) 
14. Xu, HK: Iterative methods for split feasibility problem in infinite-dimensional Hilbert spaces. Inverse Probl. 26, 105018 (2010)

15. Censor, Y, Segal, A: The split common fixed point problem for directed operators. J. Convex Anal. 16, 587-600 (2009)

16. Masad, E, Reich, S: A note on the multiple-set split feasibility problem in Hilbert space. J. Nonlinear Convex Anal. 8 , 367-371 (2007)

17. Goebel, K, Kirk, WA: A fixed point theorem for asymptotically nonexpansive mappings. Proc. Am. Math. Soc. 35 , 171-174 (1972)

doi:10.1186/1687-1812-2012-151

Cite this article as: Wang et al.: Split feasibility problems for total quasi-asymptotically nonexpansive mappings. Fixed Point Theory and Applications 2012 2012:151.

Submit your manuscript to a SpringerOpen ${ }^{\circ}$ journal and benefit from:

- Convenient online submission

Rigorous peer review

- Immediate publication on acceptance

- Open access: articles freely available online

- High visibility within the field

- Retaining the copyright to your article

Submit your next manuscript at $>$ springeropen.com 